DOI: 10.14526/2070-4798-2020-15-1-5-14

\title{
Relationships between anthropometric, spirometric, cardio-respiratory and endurance performance values among male Kenyan runners
}

\author{
Francis Mundia Mwangi \\ $(P h D)$, Lecturer, \\ Department of Physical Education, Exercise and Sports Science, Kenyatta University, \\ P.O. Box 43844 - Oo10o, Nairobi, Kenya. \\ Tel: +254722761379 \\ ORCID: oooo-ooo3-0147-9140, mwangi.francis@ku.ac.ke*
}

\begin{abstract}
Anthropometric measures such as height and age are used in equations for estimating spirometric values for various populations, while some studies have reported significant relationships between some spirometric, cardio-respiratory and endurance performance. Equations for evaluating spirometric values are usually based on data derived from samples of certain groups of people which may not be representative of the world's diverse population. This study therefore sought to determine the relationships between anthropometric, spirometric and cardio-respiratory values of Kenyan elite endurance runners. Methods. Ten (10) male purposively selected elite Kenyan runners volunteered to take part in the study. They were instrumented in anthropometric assessments, spirometry assessments, and an incremental treadmill test to exhaustion coupled with cardio-respiratory assessments. Results. Pearson correlation analyses show Pearson correlation analyses from in the current study shows significant relationships between subjects' body height and peak expiratory flow (PEF) $(\mathrm{r}=.741 ; \mathrm{p}=.002)$, forced vital capacity (FVC) $(\mathrm{r}=.640 ; \mathrm{p}=.010)$ and forced expiratory volume in one second $\left(\mathrm{FEV}_{1}\right)(\mathrm{r}=.587$; $\mathrm{p}=.021$ ). The runners' FVC and minute ventilation (VE) had significant correlation with volume of oxygen consumption $\left(\mathrm{VO}_{2}\right)$ both at submaximal $(\mathrm{p}<.01)$ and maximal levels $(\mathrm{p}<.05)$. Sitting height recorded a stronger positive association with $\mathrm{VO}_{2}(\mathrm{r}=.667 ; \mathrm{p}=.009)$ than body height $(\mathrm{r}=.564 ; \mathrm{p}=.029)$, while the latter has a stronger positive association with submaximal endurance speed $(\mathrm{r}=.668 ; \mathrm{p}=.009)$ than the former $(\mathrm{r}=.617 ; \mathrm{p}=.019)$. Dependent sample $\mathrm{t}$ test showed that spirometric values are not significantly different from predicted values ( $p>.05)$, but maximum heart rate was significantly lower than predicted $(\mathrm{p}=.001)$. Conclusion. Current spirometric prediction equations that use anthropometric variables are fairly accurate. However, more studies are needed to improve prediction and reference values for cardio-respiratory parameters. Keywords: Endurance exercise variables, Predicted values, Somatotype.
\end{abstract}

For citation: Francis Mundia Mwangi. Relationships between anthropometric, spirometric, cardiorespiratory and endurance performance values among male Kenyan runners. Russian Journal of Physical Education and Sport. 2020; 15(1): 5-13. DOI: 10.14526/2070-4798-2020-15-1-5-14

\section{INTRODUCTION}

Anthropometric measures such as height and age are used in equations for estimating/ predicting spirometric values for various populations (Hankinson, Odencrantz \& Fedan, 1999; Stanojevic et al., 2008). Most of these equations have been derived from measurements data collected from people outside Africa. On the other hand, some studies have reported positive relationships between some spirometric variables and endurance performance (Adegoke \& Arogundade, 2002; Fatemi, Shakerian, Ghanbarzade, Habibi \& Moghaddam, 2012; Pringle, Latin \& Berg, 2005). Use of equations derived from other population may lead to development of research instruments which have not been validated for the particular population, and may underrate or overrate test parameters. This can have adverse implications in health and fitness appraisal, training, as well as in performance. According to Sood, Dawson, Henkle, Hopkins-Price and Qualls (2007), ancestral background, altitude, and area of residence are some of the factors that may contribute to biological variation which may cause lack of agreement with reference values from different population.

In the last several decades (since 1968) athletes from East Africa have dominated international distance running events (International 
Association of Athletics Federation [IAAF], 2012; Larsen, 2003; Onywera, Scott, Boit \& Pitsiladis, 2006; Scott \& Pitsiladis, 2007). This is especially the case for runners from Kenya. Noakes (2001) noted that no international sport has ever been dominated by athletes from one country to the extent the Kenyans have done in international competitions from $800 \mathrm{~m}$ to the marathon, winning between 40 and $50 \%$ of all medals.

Favourable anthropometric characteristics have been touted as contributing to success of East African runners. Lucia et al. (2008), and Saunders, Pyne, Telford, and Hawley (2004) observe that reduced muscle mass below the centre of gravity (i.e. thin calves compared with Caucasians) can increase efficiency of running, and seems to be the main determinants of efficiency of human locomotion. However, the extent to which various factors contribute to Kenyan runners dominating the field remains as yet to be determined (Scott and Pitsiladis, 2007; Onywera et al., 2006; Scott et al., 2005; Pitsiladis, Onywera, Geogiades, O'Connell, W. \& Boit, 2004). This study therefore sought to determine the relationships between anthropometric, spirometric and respiratory values, and endurance performance indicators (submaximal and maximal oxygen consumption and speed) among Kenyan distance runners.

\section{MATERIALS AND METHODS}

Ten (10) purposively selected elite Kenyan runners were instrumented in anthropometric assessments, baseline spirometry and an incremental treadmill running test to exhaustion with respiratory assessments. Prior to instrumentation and baseline testing sessions, each participant signed an informed consent form and completed a physical activity readiness screening questionnaire (PAR-Q). After the inclusion criteria were met, the participants underwent basic anthropometry measurements, resting physiological measurements (ventilation [tidal volume and frequency], respiratory gases, blood pressure and heart rate), baseline spirometric tests, and a treadmill test to exhaustion with respiratory measurements regularly taken.

Anthropometric measures (heights, segments, skinfolds, girths and breaths) were taken and used to establish the general body type and composition of the participants using procedures recommended by ISAK (Marfell-Jones, Olds, Stewart \& Carter, 2006). Digital scale (Seca aura 807 , Leicester) was used for weight measurements, stadiometer (Height Measure SE001, Leicester) for height, skin fold calliper (Slimguide Body Care, England) for skin fold measurements, sliding calliper (Rosscraft Cambell 10, USA) for breaths, segmometer (Rosscraft Segmometer 4, Canada) for segments, and tape (Rosscraft Anthrotape ORC, USA) for girths.

Spirometric variables measured included forced vital capacity (FVC), forced expiratory volume in one second $\left(\mathrm{FEV}_{1}\right)$, forced expiratory volume in one second as a proportion of forced vital capacity $\left(\mathrm{FEV}_{1} / \mathrm{FVC}\right)$ and maximum inspiratory pressure (MIP). Respiratory measures obtained during treadmill test included tidal volume (VT), breathing frequency $(\mathrm{Fb})$, minute ventilation ( $\mathrm{VE})$, oxygen consumption $\left(\mathrm{VO}_{2}\right)$, carbon dioxide production $\left(\mathrm{VCO}_{2}\right)$ and respiratory exchange ratio (RER).

Participants performed 3-6 forced vital capacity maneuvers. This test involved breathing on a turbine Pneumotachograph (HR8ooL, HansRudolph, USA) from a portable spirometer system (ML 311, ADInstruments, Australia), taking several normal breaths followed by a large inspiration to total lung capacity and a full forceful expiration to residual volume. From this maneuver, researcher recorded values for the forced vital capacity (FVC), the forced expiratory volume in 1 second $\left(\mathrm{FEV}_{1}\right)$ and peak expiratory flow rates (PEF). Maximal Inspiratory (MIP) was also taken to measure the strength of the respiratory muscles using a pressure manometer (Raytech Instruments, Vancouver, BC). The measurements required the subject to breathe in as hard as possible for at least 1 second at functional residual volume.

The participants began the running test on a treadmill at a starting speed of $14 \mathrm{Kmh}^{-1}$ with no elevation (after a 5 minute warm-up at a speed of 5-8 $\mathrm{Kmhr}^{-1}$ ). Every three minutes the treadmill speed was increase by $1 \mathrm{Km} \mathrm{hr}^{-1}$ until exhaustion. The participants were made to breathe through a mouthpiece of spirometer system with nose clip fixed, allowing the measurement of ventilation 
to be made. In addition, the respired gases were analyzed using respiratory gasses analyzers (17625 and 17630, Vacumed, Ventura, California, USA) such that the amount of carbon dioxide produced and oxygen consumed was determined. Heart rate was measured and monitored using Polar heart rate monitor (S610i, Polar Electro, Kempele, Finland). The last five stages leading to maximal exercise were considered in the data analyses. Average speed for these five exercise stages leading to termination of exercise were $14.72 \pm 1.35,15.60 \pm 1.51,16.70 \pm 1.34$, $17.70 \pm 1.34,18.70 \pm 1.34(\mathrm{mean} \pm \mathrm{sd})[\mathrm{km} / \mathrm{h}]$. At the time of termination of the incremental exercise, the participants reached average speed of $18.7 \pm .34 \mathrm{Km} /$ $\mathrm{hr}$, the highest being $21 \mathrm{Km} / \mathrm{hr}$.

\section{Participants' Characteristics}

The average age of the participants was $26.90 \pm 4.175$ (mean \pm sd) and is within the range at which endurance athletes at which endurance athletes are in their prime (Schulz \& Curnow, 1988), while the BMI average was $18.376 \pm 1.624$, typical of values reported for Kenyan distance runners (Kong \& Heer, 2008). The participants' training attributes

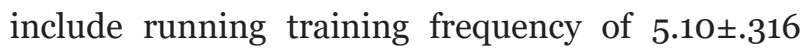
per week, training distance $12.70 \pm 5.10 \mathrm{~km}$, weekly training mileage of $111.60 \pm 44.06[\mathrm{~km}]$, and duration of competitive running of $5.10 \pm 2.02485$ (mean \pm sd) years.

\section{RESULTS AND DISCUSSION}

\section{Anthropometric Values}

The participants' anthropometric values were summarised as calculated using Heath-Carter formula as adopted in ISAK Manual (Marfell-Jones et al., 2006). The somatotype values indicate that the participants had moderate ectomorphy and mesomorphy components, with low endormorphic values (Endomorphy; 0.91 \pm 0.34 , Mesomorphy; $3.31 \pm 0.98$, Ectomorphy; $4.80 \pm 1.32)$. The values are similar to those reported by Abraham (2010) showing low endomorphic characteristi cs and with ectomorphic component highly marked among middle and long distance runners. Percent body fat by six skin folds $(5.25 \pm 0.59 \%)$ rated the participants as athletic according to established norms used in evaluating trained persons (Netfit, 2012). It showed that the runners have low levels of fat, bordering what is referred to as essential fat necessary for vital body functions. Rating of BMI (18.38 \pm 1.62$)$ and Waist to Hip Ratio (0.80 \pm 0.03$)$ shows similar trend for the athletes. The values are close to those observed by Kong and Heer (2008) who reported low body mass index (20.1 $\left.1.8\left[\mathrm{~kg}^{*} \mathrm{~m}-2\right]\right)$ and low percentage body fat $(5.1 \pm 1.6)$ among elite Kenyan distance runners.

\section{Baseline Spirometry values}

The spirometry values are summarised in descriptive measures in Table 1. Dependent sample $\mathrm{t}$ test was used to compare the baseline spirometric values against their corresponding predicted values. Prediction equations from the National Health and Nutrition Examination Survey (NHANES III) for African American were used as presented by Hankinson et al., (1999). These reference standards are based on measurements of normal subjects of similar age, height, and race. The results indicate that spirometric values are not significantly different ( $p>.05$ ) from predicted values, Prediction equations from local study by Orie (1999) yielded significantly higher values than those recorded by the current study.

Table 1 - Subjects' recorded and predicted spirometry values $(n=10)$

\begin{tabular}{cc}
\hline Spirometric Variable & $\begin{array}{c}\text { Mean } \pm \text { Std. } \\
\text { Deviation }\end{array}$ \\
\hline Peak inspiratory flow (PIF) [L/s] & $4.45 \pm 1.84$ \\
Peak expiratory flow (PEF) [L/s] & $8.57 \pm 2.34$ \\
Predicted PEF [L/s] & $9.29 \pm .58$ \\
Percentage of predicted PEF [\%] & $91.88 \pm 22.05$ \\
Forced vital capacity (FVC) [L] & $4.02 \pm .56$ \\
Predicted FVC [L] & $4.33 \pm .35$
\end{tabular}




\begin{tabular}{|c|c|}
\hline Percentage of predicted FVC [\%] & $93.11 \pm 12.62$ \\
\hline $\begin{array}{l}\text { Forced expiratory volume in one } \\
\text { second }\left(\mathrm{FEV}_{1}\right)[\mathrm{L}]\end{array}$ & $3 \cdot 39 \pm .56$ \\
\hline Predicted $\mathrm{FEV}_{1}[\mathrm{~L}]$ & $3.66 \pm .28$ \\
\hline Percentage of predicted $\mathrm{FEV}_{1}[\%]$ & $92.91 \pm 15.61$ \\
\hline $\begin{array}{c}\mathrm{FEV}_{1} \text { as a proportion of } \mathrm{FVC}\left(\left(\mathrm{FEV}_{1} /\right.\right. \\
\mathrm{FVC}) \%)[\%]\end{array}$ & $86.69 \pm 6.48$ \\
\hline $\begin{array}{l}\text { Predicted value for } \mathrm{FEV}_{1} \text { as a } \\
\text { proportion of } \mathrm{FVC}[\%]\end{array}$ & $84.32 \pm .76$ \\
\hline $\begin{array}{l}\text { Percentage of predicted value for } \mathrm{FEV}_{1} \\
\qquad / \mathrm{FVC}[\%]\end{array}$ & $102.82 \pm 7.77$ \\
\hline
\end{tabular}

\section{Cardio-Respiratory Variables}

Cardio-Respiratory values recorded at rest and during treadmill incremental exercise tests for Heart rate (HR), Percent of age-predicted maximum heart rate $\left(\% \mathrm{MHR}_{\text {Pred }}\right)$, Tidal Volume (VT), Breathing Frequency (Fb), Minute Ventilation (VE), Oxygen Consumption $\left(\mathrm{VO}_{2}\right.$ ), Carbon dioxide production $\mathrm{VCO}_{2}$, and Respiratory Exchange Ratio (RER) are summarized in Table 2. The variables values are known to increase with exercise intensity at varying rates, with sub-maximal and maximal values used to estimate fitness and metabolic statuses of the individual (Carey, Schwarz, Pliego \& Raymond, 2005; Haff \& Dumke, 2012; Plowman \& Smith, 1997). Peak values can be differentiated from maximal values in that the latter are the values recorded at the termination of exercise with or without a plateau, while the former are the highest recorded values during the exercise test duration. Robergs (2001) observes that the term $\mathrm{VO}_{2} \max$ should not be applied to the peak $\mathrm{VO}_{2}$ attained without a $\mathrm{VO}_{2}$ plateau. This can apply to the other tested variables.
Most of the resting values for the respiratory variables are within values cited by several authors. According to Elert (2001), the average values for VT is $500 \mathrm{~mL}$ for Male and $390 \mathrm{~mL}$ for Female. Mackenzie (2004) cites values of 600 and $500 \mathrm{~mL}$ for (Caucasians) male and female respectively. The author says that for a given standing height, thoraxes of people of African origin are shorter than of Caucasians of similar age, sex and height, and therefore have lower lung capacity. As for the heart rate values, one sample $t$ test comparing the recorded and age-predicted values indicate that the participants had significantly lower HR and \%HRM ( $p=.001)$ at rest and during maximal endurance running. Oxygen Consumption peak values $(3.50 \pm .26)[\mathrm{L} / \mathrm{min}]$ were significantly higher than predicted values $(p=.001)$, for people of similar age and height in general population. Relative $\mathrm{VO}_{2}$ max values $(64.4 \pm 4.9)[\mathrm{ml} / \mathrm{kg} / \mathrm{min}]$ rated superior judged on cardio-respiratory fitness classification from Physical Fitness Specialist Manual as presented in Heyward, (2006).

Table 2 - Cardio-Respiratory values for athletes at rest, at sub-maximal exercise, maximal exercise, and peak values recorded (mean $\pm \mathrm{sd}),(n=10)$.

\begin{tabular}{lrrrr}
\hline Respiratory Variable & At Rest & $\begin{array}{r}\text { At sub-maximal } \\
\text { exercise }\end{array}$ & $\begin{array}{r}\text { At maximal } \\
\text { exercise }\end{array}$ & Peak \\
\hline $\mathrm{HR}$ & $57.60 \pm 10.74$ & $176.60 \pm 9.76$ & $180.40 \pm 10.28$ & $180.40 \pm 10.28$ \\
$\% \mathrm{MHR}{ }_{\mathrm{Pred}}$ & $30.01 \pm 2.09$ & $91.50 \pm 5.62$ & $93.46 \pm 5.82$ & $93.46 \pm 5.82$ \\
$\mathrm{VT}[\mathrm{L} / \mathrm{br}]$ & $.55 \pm .14$ & $1.84 \pm .31$ & $1.87 \pm .29$ & $1.90 \pm .29$ \\
$\mathrm{Fb}[\mathrm{br} / \mathrm{min}]$ & $21.64 \pm 4.40$ & $59.28 \pm 12.27$ & $60.51 \pm 10.88$ & $61.77 \pm 11.37$ \\
$\mathrm{VE}[\mathrm{L} / \mathrm{min}]$ & $8.57 \pm 1.61$ & $79.45 \pm 10.90$ & $83.07 \pm 11.98$ & $84.24 \pm 10.14$ \\
$\mathrm{Absolute} \mathrm{VO}_{2}[\mathrm{~L} / \mathrm{min}]$ & $.29 \pm .07$ & $3.40 \pm .29$ & $3.44 \pm .35$ & $3.50 \pm .26$ \\
$\mathrm{VCO}_{2}[\mathrm{~L} / \mathrm{min}]$ & $.25 \pm .06$ & $3.41 \pm .44$ & $3.51 \pm .46$ & $3.57 \pm .41$ \\
$\mathrm{RER}_{\mathrm{Relative} \mathrm{VO}_{2}(\mathrm{ml} / \mathrm{kg} / \mathrm{min}]}$ & $.86 \pm .08$ & $1.00 \pm .07$ & $1.02 \pm .07$ & $1.02 \pm .07$ \\
& $5.30 \pm 1.10$ & $62.32 \pm 4.13$ & $63.22 \pm 6.76$ & $64.36 \pm 4.88$ \\
\hline
\end{tabular}




\section{Correlation Analyses}

Pearson correlation analyses from in the current study shows significant relationships between subjects' body height and PEF ( $r=.741$; $p=.002)$, FVC $(r=.640 ; p=.010)$ and $\mathrm{FEV}_{1}(r=.587$; $p=.021)$. The runners' FVC and VE had significant correlation with relative $\mathrm{VO}_{2}$ both at sub-maximal $(p<.01)$ and maximal levels $(p<.05)$. PEF, FVC, $\mathrm{FEV}_{1}$, VE and speed had higher correlation $(p<.05)$ with $\mathrm{VO}_{2}$ at sub-maximal than at maximal levels. Other spirometric variables (PIF, $\mathrm{FEV}_{1} / \mathrm{FVC}, \mathrm{MIP}$ ) recorded no significant relationship with subjects' body height ( $p>.05)$. Subjects' body height recorded high correlation with speed at maximal exercise level $(r=.668 ; p=.009)$ and with maximal oxygen consumption relative to body weight $\left(\mathrm{VO}_{2} \max \right)$ $(r=.564 ; p=.029)$ (Table 3). Other anthropometric variables which recorded significant correlation (inversely) with velocity/speed at maximal exercise level at $p<.01$ are waist to hip ratio (WHR) and percentage body fat.

Table 3 - Correlation analyses for subjects anthropometric variables vs speed at maximal exercise level and $\mathrm{rVO}_{2} \max (n=10)$

\begin{tabular}{|c|c|c|}
\hline Anthropometric variables & $\begin{array}{l}\text { Correlation } r \\
\text { with speed }\end{array}$ & $\begin{array}{c}\text { Correlation } \\
r \text { with } \mathrm{VO}_{2} \\
\max \end{array}$ \\
\hline $\begin{array}{l}\text { Body height (stretch } \\
\text { stature) }\end{array}$ & $.668^{* * *}$ & $.564^{*}$ \\
\hline Body weight/mass & .519 & .384 \\
\hline Body mas index (BMI) & -.044 & -.145 \\
\hline Waist girth & $.575^{*}$ & .313 \\
\hline Arm girth & .183 & .093 \\
\hline Gluteal girth (max.) & -.356 & -.515 \\
\hline Calf girth (max.) & .162 & .019 \\
\hline Waist to hip ratio (WHR) & $.739^{* *}$ & $.624^{*}$ \\
\hline \%Body fat & $-.713^{* * *}$ & $-.839^{* * *}$ \\
\hline Sum of 6 skinfolds & $-.645^{*}$ & $-.763^{* * *}$ \\
\hline Sum of 8 skinfolds & $-.630^{*}$ & $-.760^{* *}$ \\
\hline Sitting height & $.617^{*}$ & $.667^{* *}$ \\
\hline Troncherterion ht & .452 & .295 \\
\hline $\begin{array}{c}\text { Troncherterion-tibiale } \\
\text { laterale }\end{array}$ & $.568^{*}$ & .156 \\
\hline Tibiale laterale ht & .405 & .321 \\
\hline $\begin{array}{c}\text { Tibiale mediale-sphyrion } \\
\text { tibiale }[\mathrm{cm}]\end{array}$ & .345 & .167 \\
\hline Endomorphy & $-.649^{*}$ & $-.726^{* *}$ \\
\hline Mesomorphy & -.029 & -.008 \\
\hline Ectomorphy & .093 & .386 \\
\hline
\end{tabular}

* Correlation is significant at the o.05 level (2-tailed).

** Correlation is significant at the o.01 level (2-tailed). 
Waist girth, sitting height and Troncherterion-tibiale laterale recorded significant positive correlation with velocity/speed at maximal exercise level at $p<.01$, while sum of skinfolds, and endomorphic component recorded significant inverse correlation at same confident interval. These anthropometric variables also registered significant relationship with maximal oxygen consumption relative to body weight $\left(\mathrm{VO}_{2}\right.$ max $)$, with sitting height recording a stronger association than body height (Table 3). Calf girth did not register significant correlation $(r=.346 ; p=.226)$ with running economy $\left(\mathrm{VO}_{2}\right.$ at $16 \mathrm{Km} / \mathrm{hr}$ as a percentage of $\left.\mathrm{VO}_{2} \max \right)$.

Anthropometric measures have been used to establish somatotype and body composition for different purposes. These aspects in turn have been used to characterize and estimate the suitability of individuals to particular sports. The process whereby the physical demands of a sport lead to selection of body types best suited to that sport have been referred to as morphological optimization (Abraham, 2010). Spirometric measures have been used to evaluate the status of lung capacity and the concomitant effects on external and internal respiration in human (O’Donnell, Lam \&Webb, 1999; Stanojevic et al., 2008). In exercise, some studies have shown high correlation of some spirometric measures and performance in endurance events (Adegoke \& Arogundade, 2002; Fatemi et al., 2012; Pringle et al., 2005), while some have shown weak or no significant relationships (Amonette \& Dupler, 2002; Knechtle \& Kohler, 2008). Anthropometric attributes on the other hand are used in spirometric prediction equations. With most of these regression equations having been developed using data mostly from populations from outside Africa, it is important to establish the accuracy of the same not only among local populations, but also among athletes/sports participants.

Some anthropometric values of Kenyan runners have captured the interest of researchers with some of them concluding that they could be behind their dominance in endurance running. Kong and Heer (2008) reported small calf circumference $(34.5 \pm 2.3 \mathrm{~cm})$ among Kenyan distance runners and suggested that the slim limbs may positively contribute to performance by having a low moment of inertia and thus requiring less muscular effort in leg swing. The current study similarly observed small calf girth values $(33.17 \pm 1.78 \mathrm{~cm}$. However, the values showed no correlation with either maximal endurance speed at maximal exercise level ( $r=.162$; $p=.580$ ), maximal oxygen consumption ( $r=.019$; $p=.948$ ) (Table 3 ), or running economy $(r=.346$; $p=.226)$.

Sittingheightrecorded astrongerassociation with $\mathrm{VO}_{2}$ than body height at maximal exercise level (Table 3). This may be related to larger lungs, which makes it correlate highly with $\mathrm{VO}_{2}(r=.667 ; p=.009)$ and running speed $(r=.617 ; p=.019)$ (higher than troncherterion height) (Table 3). This is supported by the correspondingly high correlation between FVC and $\mathrm{VO}_{2}$ at same exercise stage $(p=.021)$, and higher correlation at sub-maximal level $(p=.002)$. Mackenzie (2004) observes that the values of $\mathrm{FEV}_{1}$ and FVC, for people of African origin are 10 to $15 \%$ lower than for Caucasians of similar age, sex and height because for a given standing height their thorax is shorter. This implies that a person with more sitting height has a taller thorax, and hence larger lungs indicated by high FVC values. Waist to hip ratio (WHR) and percentage body fat variables which recorded significant correlation (inverse) with speed at maximal exercise level at $p<.01$. This is expected because any increment in body fat and weight causes oxygen consumption to increase due to the greater energy demand required to initiate and sustain movement of a larger weight (Abraham, 2010). In addition, endurance training utilizes fat metabolism more than other forms of training (Heyward, 2006).

As for the heart rate values, one sample $t$ test comparing the recorded and age-predicted values indicate that the participants had significantly lower HR and \%HRM ( $p=.001)$ at rest and during maximal endurance running. Heart rate increases proportionately with exercise intensity (linearly with $\mathrm{VO}_{2}$ ) (Haff \& Dumke, 2012; Plowman \& Smith, 1997). The variable values are influenced by an individual's age and level of cardio-respiratory fitness. Percent of maximum heart rate (\%MHR) at rest and during exercise have been used to predict cardio-respiratory fitness, with the maximum heart rate (MHR) measured directly, or estimated from 
age-based formulae. In the current study, MHR was estimated from 220 - age formula. The subjects' average age-predicted maximum heart rate in the current study was $193.10 \pm 4.18$ (mean \pm sd) [bts/ min]. Lower heart rate is a hallmark of adaptation to endurance training (Haff \& Dumke, 2012; Plowman \& Smith, 1997). According to the authors, the reduction of HR following training results from increased stroke volume rather than reduction in $\mathrm{VO}_{2}$ or cardiac output. It is therefore logical to say that the subjects in the current study had high stroke volume.

The minute ventilation (VE) variable is normally expected to increase linearly/ proportionally with increasing exercise intensity up to about $60 \%$ of maximum effort, then more sharply (after ventilation threshold) (Haff \& Dumke, 2012). Values of $145.7 \pm 27.5 \mathrm{~L} / \mathrm{min}$ have been reported at maximal endurance treadmill tests (Carey, Pliego \& Raymond, 2008) and 162.0 $\pm 6.4 \mathrm{~L} / \mathrm{min}$ during competition (Kippelen, et al., 2005). McArdle, Katch, and Katch (2010) observe that during strenuous exercise, elite endurance athletes may increase exercise minute ventilation to $100 \mathrm{~L}$ or more (about 17 to 20 times the resting value). But it is expected that persons with superior gaseous exchange capacity will need relatively less VE at rest and during a given exercise intensity (Hallstrand, Bates \& Schoene, 2000). Values recorded during the current study are lower and may indicate favourable gas exchange status. Breathing frequency $(\mathrm{Fb})$ variable is normally expected to increase with increasing exercise intensity. Together with increased tidal volume, the variables account for the increased VE. Synchronisation of breathing action with running rhythm is important at high intensity endurance exercise for efficiency (Harriman, 2011), while $\mathrm{Fb}$ and $\mathrm{VE}$ have been shown to significantly correlate to $\mathrm{VO}_{2} \max$ (Carey et al., 2008). Values of $48.3 \pm 5.7$ breaths per min have been reported for endurance runners during treadmill tests and $51.7 \pm 6.7$ during cycle ergometry (Carey et al., 2008). McArdle et al., (2010) observe that during strenuous exercise, elite endurance athletes breathe as rapidly as 60 to 70 times each minute during maximal exercise. With tidal volume of 2.0 $\mathrm{L}$ and above occurring during exercise, such increases in breathing rate and Vt may increase exercise minute ventilation to $100 \mathrm{~L}$ or more (about 17 to 20 times the resting value). Values recorded during maximal exercise in the current study are therefore typical, and indicates similar trend, with $\mathrm{VE}$ registering significant association with $\mathrm{VO}_{2}$ at maximal exercise stage.

The Respiratory exchange ratio (RER) is normally expected to increase with increasing exercise intensity. Values of over $\mathbf{1 . 2}$ have been reported in maximal endurance exercise, with values higher than 1.0 used as criterion for accepting test trial as maximal (Haff \& Dumke, 2012). Values recorded during the current study indicate that the participants exerted themselves to reach maximal effort at the termination of the exercise.

Absolute Oxygen Consumption $\left(\mathrm{VO}_{2}\right)$ peak values $(3.50 \pm .26)[\mathrm{L} / \mathrm{min}]$ were significantly higher than predicted values ( $p=.001$ ), for people of similar age and height in general population. Relative $\mathrm{VO}_{2}$ max values (64.4 \pm 4.9$)$ [ml/kg/min] rated superior judged on cardio-respiratory fitness classification from the Physical Fitness Specialist Manual as presented in Heyward, (2006). There is relatively high rate of oxygen consumption which can be sustained, given that sub-maximal value of relative $\mathrm{VO}_{2}$ do not differ significantly from maximal value $(p=.739)$.

\section{CONCLUSION}

From the findings of the study the researcher concludes that some anthropometric measures (stature, sitting height, BMI) have significant relationship with some spirometric variables (FVC, $\mathrm{PEF}, \mathrm{FEV}_{1}$ ) and endurance exercise performance variables (speed and $\mathrm{VO}_{2}$ ) among Kenyan distance runners. Sitting height has a stronger positive association with $\mathrm{VO}_{2}$ than body height, while the latter has a stronger positive association with speed than former among these athletes. The runners' somatotype mainly consists of moderate ectomorph and mesomorph with low endomorph components.

Kenyan distance runners' spirometric values can be approximated by commonly used equations. However, there is need to establish local norms for more accurate interpretations of these data. Significant correlation exists between some 
anthropometric, spirometric and sub-maximal endurance running performance variables. These variables can be used to predict endurance running performance, but in cohort with other factor/s which may be yet to be determined. Ventilatory responses of Kenyan runners can be able to support relatively high intensity endurance performance through both increased breathing rate and tidal volume. Breathing frequency however indicates some potential which may be tapped for better performance in endurance exercise through training.

Kenyan endurance runners have excellent and superior oxygen consumption (aerobic capacity) when rated against commonly used norms. They utilise relatively low percentage of their maximum heart rate during sub-maximal and maximal endurance exercise. This must have been accompanied by large stroke volume (and thus a strong and/or versatile heart. With their pulmonary function being able to support delivery demands of superior oxygen consumption at submaximal and maximal endurance exercise despite being comparable to values from other population, it is possible that they could be having enhanced gaseous exchange capacity such as more pulmonary capillalisation and / or less shunts.

Given the high significant correlation between some spirometric variables (FVC, VE) and endurance performance indicators (sub-maximal velocity and $\mathrm{VO}_{2}$ ), the study recommends using these parameters in cohort with other factor/s such as velocity at $\mathrm{VO}_{2}$ max to tell apart athletes' potential in endurance performance in middle and long distance races. More studies need to be done in this area to determine the extent anthropometric and cardiorespiratory parameters of Kenyan distance runners compares to those of runners from other regions, the source of the differences and their overall contribution to endurance running performance. While the existing spirometric prediction equations that use anthropometric variables are fairly accurate, more studies are needed to improve prediction equations for cardio-respiratory parameters as well as develop locally generated norms.

\section{Acknowledgement}

My appreciation for the study volunteer athletes and the research assistants.

\section{REFERENCES}

1. Abraham G. Analysis of anthropometry, body composition and performance variables of young Indian athletes in southern region. Indian Journal of Science and Technology. 2010; 3(12): 1210-1213.

2. Adegoke O.A., Arogundade O. The effect of chronic exercise on lung function and basal metabolic rate in some Nigerian athletes. African Journal of Biomedical Research. 2002; 5(1-2): 9-11.

3. Amonette W.E., Dupler T.L. The effects of respiratory muscle training on $\mathrm{VO}_{2}$ max, the ventilator threshold and pulmonary function. Journal of Exercise Physiology. 2002; 5(2): 29-35.

4. Carey D.G., Pliego G.J., Raymond R.L. How Endurance Athletes Breathe During Incremental Exercise to Fatigue: Interaction of Tidal Volume and Frequency. Journal of Exercise Physiology. 2008; 11(4): 44-51.

5. Carey D.G., Schwarz L.A., Pliego G.J., Raymond R.L. Respiratory rate is a valid and reliable marker for the anaerobic threshold: implications for measuring change in fitness. Journal of Sports Science and Medicine. 2005; 4, 482-488.

6. Elert G. Volume of Human Lungs. 2001. URL: http://hypertextbook.com/facts/2001/ LaurenCalabrese.shtml

7. Fatemi R., Shakerian S., Ghanbarzade M., Habibi A., Moghaddam, H.F. The comparison of dynamic volumes of pulmonary function between different levels of maximal oxygen uptake. International Research Journal of Applied and Basic Sciences. 2012; 3(3): 667-674.

8. Haff G., Dumke C. Laboratory manual for exercise physiology. Champaign: Human Kinetics. 2012.

9. Hallstrand T.S., Bates P.W., Schoene R.B. Aerobic Conditioning in Mild Asthma Decreases the Hyperpnea of Exercise and Improves Exercise and Ventilatory Capacity. Chest. 2000; 118: 1460-1469.

10. Hankinson J.L., Odencrantz J.R., Fedan K.B. Spirometric reference values from a sample of the general U.S. population. American Journal of Respiratory and Critical Care Medicine. 1999; 159: 179-187.

11. Harriman D. Proper Breathing for Running. 2011. URL: http://www.livestrong.com/ article/223203-proper-breathing-for-running/

12. Heyward V.H. Advanced Fitness Assessment and Exercise Prescription 5th ed. Champaign, Human Kinetic. 2006.

13. International Association of Athletics Federation [IAAF]. Official Results: All Time List (Online). 2012. URL: http://www.iaaf.org/mm/ Document/06/60/70/66070_PDF_English.pdf

14. Kippelen P., Caillaud C., Robert E., Connes P., Godard P., Prefaut C. Effect of endurance 
training on lung function: a one-year study. British Journal of Sports Medicine. 2005; 39: 617-621.

15. Knechtle B., Kohler G. Running performancenotanthropometricfactorsis associated with race success in a Triple Iron Triathlon. British Journal of Sports Medicine. 2008. URL: http:// bjsm.bmj.com/content/early/2008/01/23/ bjsm.2007.039602.full.pdf + html

16. Kong P.W., Heer H. Anthropometric, gait and strength characteristics of Kenyan distance runners. Journal of Sports Science and Medicine. 2008; 7: 499-504.

17. Larsen H.B. Kenyan dominance in distance running. Comparative Biochemistry and Physiology - Part A: Molecular and Integrative Physiology. 2003; 136(1): 161-70.

18. Lucia A., Esteve-Lanao J., Oliva'n J., Go'mez-Gallego F., SanJuan A.F., Santiago C., ... Foster C. Physiological characteristics of the best Eritrean runners -exceptional running economy. Applied Physiology, Nutrition, and Metabolism. 2006; 31: 530-540.

19. Mackenzie B. Measurement of Ventilatory Function. 2004. URL: http://www. brianmac.co.uk/spirometer.htm

20. Marfell-Jones M., Olds T., Stewart A., Carter J.E.L. International Standards for Anthropometric Assessment. Adelaide: ISAK. 2006.

21. McArdle W.D., Katch F.I., Katch V.L. Exercise Physiology: Nutrition, Energy, and Human Performance. Philadelphia: Lippincott Williams \& Wilkins. 2010.

22. Netfit. Body Fat Percentage. 2012. URL: http://www.netfit.co.uk/fitness/test/body -fatpercentage.htm? $\mathrm{p}=2$.

23. Noakes T. Physiological Capacity of the Elite Runner: in Running \& Science. Institute of Exercise and Sport Sciences: University of Copenhagen. 2001.

24. O’Donnell D.E., Lam M., Webb K.A. Spirometric correlates of improvement in exercise performance after anticholinergic therapy in chronic obstructive pulmonary disease. American Journal of Respiratory and Critical Care Medicine. 1999; 160: 542-549.

25. Onywera, V., Scott, R., Boit, M., \& Pitsiladis, Y. Demographic characteristics of elite Kenyan endurance runners. Journal of Sports
Science. 2006; 24(4): 415-422.

26. Orie N.N. Comparison of normal respiratory function values in young Kenyans with those of other Africans and Caucasians. East African Medical Journal. 1999; 76(1): 31-34.

27. Pitsiladis Y., Onywera V., Geogiades E., O'Connell W., Boit, M. The dominance of Kenyans in distance running: Equine and Comparative Exercise Physiology. 2004; 1(4): 285-291.

28. Plowman S.A., Smith D.L. Exercise physiology for health, fitness and performance. Boston: Allyn and Bacon. 1997.

29. Pringle E.M., Latin R.W., Berg K. The relationship between $10 \mathrm{~km}$ running performance and pulmonary function. Journal of Exercise Physiology. 2005; 8(5): 22-28.

30. Robergs R.A. An exercise physiologist's "contemporary" interpretations of the "ugly and creaking edifices" of the $\mathrm{VO}_{2}$ max concept. Journal of Exercise Physiology. 2001; 4(1): 1-44.

31. Saunders P.U., Pyne D.B., Telford R.D., Hawley J.A. Reliability and variability of running economy in elite distance runners. Medicine and Science in Sports and Exercise. 2004; 36(11): 19721976.

32. Schulz R., Curnow C. Peak performance and age among superathletes: track and field, swimming, baseball, tennis, and golf. The Journal of Gerontology. 1988; 43(5): 113-20.

33. Scott R., Pitsiladis Y. Genotypes and distance running: Clues from Africa. Sports Medicine. 2007; 37(4-5):424-427.

34. Scott R., Moran C., Wilson R., Onywera V., Boit M., Goodwin W., ... Pitsiladis Y. No association between Angiotensin Converting Enzyme (ACE) gene variation and endurance athlete status in Kenyans. Comparative Biochemistry and Physiology. 2005; 141(2): 169-175.

35. Sood A., Dawson B.K., Henkle J.Q., Hopkins-Price P., Qualls C. Effect of change of reference standard to NHANES III on interpretation of spirometric 'abnormality' International Journal of COPD. 2007; 2(3): 361-367.

36. Stanojevic S., Wade A., Stocks J., Hankinson J., Coates A.L., Pan H., ... Cole T.J. Reference ranges for spirometry across all ages. American Journal of Respiratory and Critical Care Medicine. 2008; 177: 253-260.

\section{Submitted: 12.01.2020}

Author's information:

Francis Mundia Mwangi - PhD, Lecturer, Department of Physical Education, Exercise and Sports Science, Kenyatta University, Nairobi, Kenya, 43844-oo10o, e-mail: mwangi.francis@ku.ac.ke 